\title{
Treatment Adherence of Patients with Rheumatoid Arthritis during COVID-19 Pandemic
}

\author{
Syamasis Bandyopadhyay*, Susobhan Mondal \\ Apollo Gleneagles Hospital, Kolkata, India \\ Email: *sambando@yahoo.co.uk
}

How to cite this paper: Bandyopadhyay, S. and Mondal, S. (2021) Treatment Adherence of Patients with Rheumatoid Arthritis during COVID-19 Pandemic. Open Journal of Rheumatology and Autoimmune Diseases, 11, 106-114.

https://doi.org/10.4236/ojra.2021.113013

Received: May 22, 2021

Accepted: August 21, 2021

Published: August 24, 2021

Copyright $\odot 2021$ by author(s) and Scientific Research Publishing Inc. This work is licensed under the Creative Commons Attribution International License (CC BY 4.0).

http://creativecommons.org/licenses/by/4.0/

\begin{abstract}
India is no exception to the economic setback due to coronavirus disease 2019 (COVID-19). Loss of jobs and income dramatically impacts the health care cost of chronic disease management. Rheumatoid arthritis is a chronic condition with a high-cost implication. With the outbreak of COVID-19, there is uncertainty about continuing immunosuppressive therapy for rheumatoid arthritis for several reasons. In this milieu, we undertook a prospective observational study to observe the use of Janus Kinase (JAK) inhibitors in a hospital-based rheumatology service in Eastern India during the pandemic period (21 March 2020 to 31 July 2020). Forty-two patients with rheumatoid arthritis were receiving treatment with JAK inhibitors. Twenty-four patients visited the Outpatient Department (OPD) during the COVID-19 pandemic. All of them were COVID-negative, but few of the patients had influenza-like symptoms. Patients faced up to a $25 \%$ reduction in their annual income during the COVID-19 pandemic. Of 24 patients, four patients had stopped treatment with JAK inhibitors owing to financial constraints or initial non-availability of medications during the lockdown. In this study, adherence to JAK inhibitors was substantially high even in the face of income curtailment during the COVID-19 pandemic.
\end{abstract}

\section{Keywords}

COVID-19, Rheumatoid Arthritis, Janus Kinase, JAK Inhibitors, Disease-Modifying Antirheumatic Drugs, Adherence, Cost

\section{Introduction}

The world is witnessing a substantial economic impact of coronavirus disease 2019 (COVID-19), and India, a developing country, is no exception. COVID-19 
has slowed down the Indian economic growth to $3.1 \%$ Gross Domestic Product (GDP) in January-March 2020. As in May 2020, the CRISIL's expert projected that the Indian economy might shrink by 5\% GDP in the fiscal year 2021 [1]. According to the Centre for Monitoring Indian Economy (CMIE) report, during the lockdown, an estimated 14 crore (140 million) people lost employment, among which 91.3 million were small traders and laborers, 18.2 million were entrepreneurs, and 17.8 million were salaried employees [2] [3]. Therefore, during any epidemic situation, self-funding for chronic disease management could have a setback and affect treatment adherence and outcomes.

Rheumatoid arthritis is one such chronic disease wherein the medical expense towards its management is substantial. Medication alone accounts for $40 \%$ of the total cost of managing the disease [4]. Moreover, out-of-pocket expenditure towards medication is one of the reasons for non-adherence [5].

Non-adherence could negatively affect the treatment outcome. In addition, the outbreak of COVID-19 has led to uncertainty about the treatment of rheumatoid arthritis with immunosuppressive medications, which can predispose the patients to infections. Patients with rheumatological diseases or on immunosuppressive therapies are at higher risk for infections. According to a retrospective longitudinal cohort study, the risk of confirmed infections, infections needing hospitalization, and any documented infection increased by $70 \%, 83 \%$, and $45 \%$, respectively, in patients with rheumatoid arthritis [6]. A prospective longitudinal study confirmed that patients with rheumatoid arthritis had a 50\% higher risk of contracting severe infections than non-inflammatory rheumatic and musculoskeletal diseases. Specific attributes of rheumatoid arthritis-immunepathogenesis of the disease, comorbidities, or treatment with immunosuppressants increase the risk for infections [7]. On the contrary, evidence also suggests that sustained remission can alleviate the risk of severe infections in patients with rheumatoid arthritis [8].

To overcome the risk of infection, in the milieu of COVID-19, the German Society of Rheumatology and the American College of Rheumatology (ACR) have issued recommendations of continuing immunosuppressive therapy despite concerns of increased susceptibility to infections [9] [10]. Moreover, interruption or reduction of immunosuppression would increase the risk of relapse, consequently increases the risk of infection.

Traditionally, rheumatoid arthritis is managed with Disease-Modifying Antirheumatic Drugs (DMARDs). In addition, a small proportion of non-responders to DMARDs are offered biological agents like Tumor Necrosis-alpha (TNF- $\alpha$ ) blockers, anti-CD20 monoclonal antibodies, and small molecules. The COVID-19 pandemic limited the patient's access to healthcare workers and facilities and forced rheumatologists to resort to electronic consultation. Consequently, patients had no access to injectable medications during the initial phase of the lockdown period. Hence, there was a surge in the use of oral medications. The Janus Kinase (JAK) inhibitors are target synthetic DMARDs (tsDMARDs), which target upstream 
protein tyrosine kinases, have been licensed to be used in rheumatoid arthritis [11] [12]. In India, among tsDMARDS, tofacitinib, a JAK 3/1/2 antagonist, and baricitinib, a JAK1/2 inhibitor, are the two commercially available oral therapy for rheumatoid arthritis. However, the cost is a significant challenge for prescribing these agents in India. Therefore, this study aimed to observe the use of JAK inhibitors in a hospital-based rheumatology service in eastern India during the pandemic period.

\section{Methods}

Data of all patients enrolled (physically or electronically) under active follow-up in the Rheumatology Outpatient Department (OPD) of our hospital were analyzed during the COVID-19 lockdown period (21 March 2020 to 31 July 2020). We audited the records of patients with a confirmed diagnosis of rheumatoid arthritis, receiving a regular small molecule, the JAK inhibitors, for 6 months or more. In addition, we administered a questionnaire to all patients (Annexure 1) to understand the impact of COVID-19 on the treatment of rheumatoid arthritis. Data from the questionnaire and medical records related to demographic, clinical, laboratory, drug history, and current treatment were compiled in tabular format. Data were analyzed using Microsoft Excel.

\section{Results and Observations}

Of 42 patients with rheumatoid arthritis who received treatment with JAK inhibitors, 24 patients were seen in OPD during the COVID-19 pandemic. Eight patients were men. The patients ranged from 38 and 76 years. The average distance of their place of residence from the hospital was about $28 \mathrm{~km}$ (range 1 to $54 \mathrm{~km})$. Most patients were graduates. Patients $(\mathrm{n}=24)$ visited the hospital during the lockdown for various reasons (Table 1) - discuss blood reports, worsening pain/symptoms, fear of COVID infection, and discontinuation of expensive medications because of the financial setbacks in the lockdown period. The financial status of patients is shown in Table 2. Patients faced up to a $25 \%$ reduction in their annual income. A higher proportion of patients in the 10 Lakhs - 25 Lakhs per annum income had a $15 \%$ reduction in their income.

Of 24 patients who visited the OPD, six had a recent history of influenza-like symptoms (Table 3), and five had an abnormal chest X-ray. Of these five patients, two required high-resolution computed tomography (HRCT) of chest and pulmonologist referral. Four patients needed a reverse transcription-polymerase chain reaction (RT-PCR) test for COVID 19, and all were COVID RT-PCR negative. The average-C-reactive protein (CRP) was $0.8 \pm 0.4 \mathrm{mg} / \mathrm{dL}$, and the disease activity score (DAS) 28 was $2.9 \pm 1$ (Table 4 ).

Of 24 patients, four patients had stopped treatment with JAK inhibitors due to the drug's financial restriction and initial non-availability during the lockdown.

Of 24 patients, 22 were receiving concomitant methotrexate, and two were on steroid therapy. 
Table 1. Profile of patients visiting the rheumatology department during the lockdown.

\begin{tabular}{|c|c|c|}
\hline \multicolumn{2}{|c|}{ Patients on small molecule over last 6 months $(\mathrm{N})$} & 42 \\
\hline \multicolumn{2}{|c|}{ Patients on small molecules visiting the hospital during lockdown $(\mathrm{N})$} & 24 \\
\hline \multicolumn{2}{|c|}{ Male (N) } & 8 \\
\hline \multicolumn{2}{|c|}{ Age, range (years) } & $38-76$ \\
\hline \multicolumn{2}{|c|}{ The average distance of residence from the outpatient department } & $28 \mathrm{~km}$ \\
\hline \multicolumn{2}{|c|}{ Average educational background } & Graduation \\
\hline Annual Income (Pre COVID) & Annual Income (Post COVID) & Number of patients \\
\hline 5 Lakhs - 10 Lakhs & Average $10 \%$ Decrement & 3 \\
\hline 10 Lakhs - 25 Lakhs & Average $15 \%$ Decrement & 14 \\
\hline 25 Lakhs - 50 Lakhs & Average $25 \%$ Decrement & 6 \\
\hline Above 50 Lakhs & $25 \%$ Decrement & 1 \\
\hline
\end{tabular}

Table 3. Patients with symptoms of influenza-like illness.

\begin{tabular}{cl}
\hline No of patients with fever & 2 \\
No of patients with shortness of breath & 2 \\
No of patients with diarrhea & 1 \\
No of patients with a sore throat & 2 \\
No of patients with cough & 4 \\
\hline
\end{tabular}

Table 4. Laboratory findings during COVID-19.

\begin{tabular}{cc}
\hline Laboratory parameter & Values \\
\hline Average erythrocyte sedimentation rate & $28 \pm 4.2 \mathrm{~mm} / \mathrm{h}$ \\
Average C-reactive protein & $0.8 \pm 0.4 \mathrm{mg} / \mathrm{L}$ \\
Average disease activity score & $2.9 \pm 1.2$ \\
Average neutrophil count & $7100 \pm 340 \mathrm{cells} / \mu \mathrm{L}$ \\
Average lymphocyte & $3100 \pm 180 \mathrm{cells} / \mu \mathrm{L}$ \\
Serum glutamic pyruvic transaminase & $42 \pm 6(\mathrm{U} / \mathrm{L})$ \\
Creatinine & $0.8 \pm 0.26 \mathrm{mg} / \mathrm{dL}$ \\
Hemoglobin & $10.8 \pm 1.2 \mathrm{~g} \%$ \\
\hline
\end{tabular}

\section{Discussion}

We found that only about $15 \%$ of patients failed to continue JAK inhibitors due to financial reasons. Self-funding patients with chronic conditions appear to continue treatment even in difficult times.

Treatment interruption could set off a vicious cycle of infection-flareimmunosuppression therapy [13]. Hence, control of disease activity is critical in patients with rheumatoid during the COVID-19 pandemic. However, in the milieu of the 
COVID-19 pandemic, treatment adherence in patients with rheumatoid arthritis could be compromised by several factors-the apprehension about immunosuppression status and risk of COVID-19, COVID-19 infection in patients with rheumatoid arthritis, shortage of medications, and cost of medications.

Biological DMARDs, including JAK inhibitors, are the newer class of drugs often used in conjunction with other DMARDs. JAK inhibitors intrude the JAKSignal Transducer and Activator of Transcription (STAT) pathway associated with immune response and alleviate the inflammatory process in rheumatoid arthritis [14] [15]. Immunosuppression status is suspected as a risk factor for COVID-19 infection. However, a review of reports on patients with underlying rheumatological diseases confirms that patients on immunosuppression are not at risk of COVID [13]. Treatment interruption can compromise control of disease activity and predispose patients to infections. Infections, in turn, aggravate rheumatoid arthritis leading to a flare warranting immunosuppression therapy. Therefore, patients with stable disease need not discontinue treatment with steroids or DMARDs until they are infected with COVID-19. In the event of contracting COVID-19, patients can temporarily stop the treatment. The ACR guideline suggests resumption of treatment with DMARDs/other biologicals within 7 - 14 days of symptom resolution and after 10 - 17 days in asymptomatic COVID-19positive patients [11]. Biological DMARDs used in the treatment of rheumatoid arthritis are also being tried in COVID-19 patients. The ACR guidelines recommend that patients continue therapy with biological DMARDs and switch to an alternative DMARD in case of shortage or non-availability of medications [10]. In this retrospective analysis, none of the 24 patients on JAK inhibitors suffered from COVID-19 during the pandemic. Most of the patients in our study were educated and hence understood the importance of continuing the treatment.

Treatment with JAK inhibitors is generally expensive than methotrexate but is cost-effective compared to adalimumab or etanercept [15] [16]. On average, our patients had nearly one-fifth (18.75\%) reduction in annual income. However, despite the financial restriction, patients could afford to continue treatment with JAK inhibitors.

Moreover, changes in access to healthcare, online consultation, anxiety, and social isolation aggravate the disease and affect the patients with rheumatoid arthritis [17]. Although it was difficult for patients in our study to attend the OPD during the COVID-19 lockdown, a substantial percentage of patients did manage to consult in OPD by traveling nearly $30 \mathrm{Km}$ from the hospital.

Adherence to DMARDs has been an issue under ordinary situations (without any pandemics). In a study from Egypt by Mahran et al., $65 \%$ of patients showed high, and $26 \%$ showed moderate adherence to DMARDs [18]. In contrast, a study from the Netherlands in 2004-2005 showed that $40 \%$ of the patients were non-adherent to DMARD. Another study showed that non-adherence to DMARDs in chronic rheumatic conditions is a substantial problem and side-effects or costs were the main contributors to non-adherence [19]. However, even in the face of a pandemic-associated low economic situation, the percentage of discontinuation of 
JAK inhibitors was low our study. A few studies have reported the treatment adherence to DMARDs during the COVID-19 pandemic.

A study from the East Azarbaijan province of Iran reported that non-adherence to anti-rheumatoid medications was uncommon within 6 months after the beginning of COVID-19. Most of the patients were diagnosed with rheumatoid arthritis $(\mathrm{n}=396 / 858[46.5 \%])$. Of 858 patients, $82(9.6 \%)$ were treated with DMARDs, and 31 patients (37.8\%) were non-adherent to DMARDs. The main reason for treatment non-adherence was fear of the immunosuppressive effects of medications [20]. Another study from Latin America analyzed the response from 345 patients with rheumatic disease to an electronic survey conducted during the COVID-19 pandemic May 14-25, 2020 [21]. In this study, most patients were diagnosed with rheumatoid arthritis $(n=177[51.3 \%])$. However, very few patients were receiving biologic or tsDMARDs $(\mathrm{n}=25[7.2 \%])$. Nearly $85 \%(\mathrm{n}=$ 293) of the respondents had not changed their medications. Among those who changed medications, $48.1 \%(\mathrm{n}=25)$ changed due to lack of availability of medications and $25 \%(\mathrm{n}=13)$ for fear of contracting COVID-19, respectively [21]. During 16 March 2020 and 3 April 2020, 656 patients with inflammatory were included in a survey conducted in Germany during the pandemic. Over $90 \%$ of the patients confirmed that they would continue the treatment even during the COVID-19 pandemic. In addition, most of them (56\%) had rheumatoid arthritis [22]. The individual patient's decision to continue DMARD therapy reflects the trusting relationship between patients and their doctors. In our study, nearly $85 \%$ of the patients continued treatment with JAK inhibitors. In this study, treatment continuation with JAK inhibitors, despite a reduction of income, could perhaps be due to the significant beneficial effect of the drugs on disease activity as evidenced by low average-C-reactive protein (CRP) and disease activity score (DAS) 28 [15].

As the sample size was small, further studies are needed to assess the treatment adherence to JAK inhibitors during the COVID-19 pandemic.

\section{Conclusion}

Adherence to JAK inhibitors was substantially high even in the face of income curtailment during the COVID-19 pandemic. This study shows that cost may not be a limiting factor for urban educated patients, especially when the treatment is effective.

\section{Author Contributions}

SB and SM both have collected data and written the manuscript.

\section{Acknowledgements}

All named authors meet the International Committee of Medical Journal Editors (ICMJE) criteria for authorship for this manuscript, take responsibility for the integrity of the work, and have given final approval for the version to be pub- 
lished. The authors thank Dr. Punit Srivastava of Mediception Science Pvt. Ltd. (https://www.mediception.com/) for providing medical writing support in the preparation of this manuscript, funded by Zydus-Cadila India.

\section{Conflicts of Interest}

The authors declare no conflicts of interest regarding the publication of this paper.

\section{References}

[1] Minus-Five (2020). https://www.crisil.com/content/dam/crisil/our-analysis/reports/Research/document s/2020/05/minus-five.pdf

[2] Vyas, M. (2020) The Jobs Bloodbath of April 2020. Centre for Monitoring Indian Economy (CMIE), Mumbai. https://www.cmie.com/kommon/bin/sr.php?kall=warticle\&dt=2020-05-05 \%2008:22:21\&msec $=776 \& v e r=p f$

[3] Vyas, M. (2020) Podcast: How Has India's Lockdown Impacted Unemployment Rates and Income Levels? https://scroll.in/article/959756/podcast-how-has-indias-lockdown-impacted-unemp loyment-rates-and-income-levels

[4] Alex, V., Cheruvallikatti, S., Abraham, S., et al. (2015) Cost of Illness of Rheumatoid Arthritis in South India. World Journal of Pharmaceutical Research, 4, 1305-1316.

[5] Heidari, P., Cross, W., Weller, C., Nazarinia, M. and Crawford, K. (2019) Medication Adherence and Cost-Related Medication Non-Adherence in Patients with Rheumatoid Arthritis: A Cross-Sectional Study. International Journal of Rheumatic Diseases, 22, 555-566. https://doi.org/10.1111/1756-185X.13549

[6] Doran, M.F., Crowson, C.S., Pond, G.R., et al. (2002). Frequency of Infection in Patients with Rheumatoid Arthritis Compared with Controls: A Population-Based Study. Arthritis \& Rheumatology, 46, 2287-2293. https://doi.org/10.1002/art.10524

[7] Mehta, B., Pedro, S., Ozen, G., et al. (2019) Serious Infection Risk in Rheumatoid Arthritis Compared with Non-Inflammatory Rheumatic and Musculoskeletal Diseases: A US National Cohort Study. RMD Open, 5, e000935. https://doi.org/10.1136/rmdopen-2019-000935

[8] Accortt, N.A., Lesperance, T., Liu, M., et al. (2018) Impact of Sustained Remission on the Risk of Serious Infection in Patients with Rheumatoid Arthritis. Arthritis Care \& Research (Hoboken), 70, 679-684. https://doi.org/10.1002/acr.23426

[9] Schulze-Koops, H., Specker, C., Iking-Konert, C., et al. (2020) Preliminary Recommendations of the German Society of Rheumatology (DGRh eV) for the Management of Patients with Inflammatory Rheumatic Diseases during the SARS-CoV-2/ COVID-19 Pandemic. Annals of the Rheumatic Diseases, 79, 840-842. https://doi.org/10.1136/annrheumdis-2020-217628

[10] Mikuls, T.R., Johnson, S.R., Fraenkel, L., et al. (2020) American College of Rheumatology Guidance for the Management of Rheumatic Disease in Adult Patients during the COVID-19 Pandemic: Version 1. Arthritis \& Rheumatology, 72, 1241-1251. https://doi.org/10.1002/art.41301

[11] Mogul, A., Corsi, K., McAuliffe, L. (2019) Baricitinib: The Second FDA-Approved JAK Inhibitor for the Treatment of Rheumatoid Arthritis. Annals of Pharmacotherapy, 53, 947-953. https://doi.org/10.1177/1060028019839650 
[12] Wollenhaupt, J., Silverfield, J., Lee, E.B., et al. (2014) Safety and Efficacy of Tofacitinib, an Oral Janus Kinase Inhibitor, for the Treatment of Rheumatoid Arthritis in Open-Label, Long-Term Extension Studies. The Journal of Rheumatology, 41, 837-852. https://doi.org/10.3899/jrheum.130683

[13] Roongta, R. and Ghosh, A. (2020) Managing Rheumatoid Arthritis during COVID-19. Clinical Rheumatology, 39, 3237-3244. https://doi.org/10.1007/s10067-020-05358-Z

[14] Bullock, J., Rizvi, S., Saleh, A., et al. (2018) Rheumatoid Arthritis: A Brief Overview of the Treatment. Medical Principles and Practice, 27, 501-507. https://doi.org/10.1159/000493390

[15] Harrington, R., Al Nokhatha, S.A. and Conway, R. (2020) Jak Inhibitors in Rheumatoid Arthritis: An Evidence-Based Review on the Emerging Clinical Data. Journal of Inflammation Research, 13, 519-531. https://doi.org/10.2147/JIR.S219586

[16] Angelini, J., Talotta, R., Roncato, R., et al. (2020) JAK-Inhibitors for the Treatment of Rheumatoid Arthritis: A Focus on the Present and an Outlook on the Future. Biomolecules, 10, 1002. https://doi.org/10.3390/biom10071002

[17] D’Silva, K.M. and Wallace, Z.S. (2021) COVID-19 and Rheumatoid Arthritis. Current Opinion in Rheumatology, 33, 255-261.

https://doi.org/10.1097/BOR.0000000000000786

[18] Mahran, S.A., Khedr, T.M., Mohammed, E.M., et al. (2020) Medication Adherence to Disease-Modifying Antirheumatic Drugs among Patients with Rheumatoid Arthritis at Assiut University Hospital, Egypt. Egyptian Rheumatology and Rehabilitation, 47, Article No. 3. https://doi.org/10.1186/s43166-020-00005-6

[19] Pasma, A., Schenk, C., Timman, R., et al. (2017) Does Non-Adherence to DMARDs Influence Hospital-Related Healthcare Costs for Early Arthritis in the First Year of Treatment? PLoS ONE, 12, e0171070. https://doi.org/10.1371/journal.pone.0171070

[20] Khabbazi, A., Kavandi, H., Paribanaem, R., et al. (2020) Adherence to Medication in Patients with Rheumatic Diseases during COVID-19 Pandemic. Annals of the Rheumatic Diseases, 80, e86. https://doi.org/10.1136/annrheumdis-2020-218756

[21] Pineda-Sic, R.A., Galarza-Delgado, D.A., Serna-Peña, G., et al. (2020) Treatment Adherence Behaviours in Rheumatic Diseases during COVID-19 Pandemic: A Latin American Experience. Annals of the Rheumatic Diseases, 80, e85. https://doi.org/10.1136/annrheumdis-2020-218791

[22] Schmeiser, T., Broll, M., Dormann, A., et al. (2020) A Cross Sectional Study on Patients with Inflammatory Rheumatic Diseases in Terms of Their Compliance to Their Immunsuppressive Medication during COVID-19 Pandemic. Zeitschrift für Rheumatologie, 79, 379-384. (In German) https://doi.org/10.1007/s00393-020-00800-8 


\section{Annexure 1. Questions Administered to Patients with Rheumatoid Arthritis}

1. Name of patient:

2. Sex: $\square$ Male $\square$ Female

3. Age:

4. Education: $\square$ No formal education $\square$ Studied up to $10^{\text {th }}$ or $12^{\text {th }}$ grade $\square$ Graduated $\square$ Post-graduate

5. Employment status: $\square$ Currently unemployed $\square$ Business/self-employed $\square$ Employed in private or government organisation

6. Native place:

7. Average distance of residence from hospital: $\mathrm{Kms}$

8. Average income (Pre-COVID-19): $\square 5$ Lakhs - 10 Lakhs $\square 10$ Lakhs - 25 Lakhs $\square 25$ Lakhs - 50 Lakhs $\square$ Above 50 Lakhs

9. Average decrement in income due to COVID-19: $\square$ No change $\square$ 10\% Decrement $\square$ 15\% Decrement $\square 25 \%$ Decrement

10. Symptoms of influenza-like illness:

$\square$ Fever $\square$ Shortness of breath $\square$ Diarrhoea $\square$ Sore throat $\square$ Cough

11. Laboratory report: $\square$ Attached $\square$ Not attached

12. Details of current treatment:

13. Are you taking any of the following medications for rheumatoid arthritis: $\square$ Baricitinib $\square$ Tofacitinib

14. Are you willing to continue treatment with baricitinib or tofacitinib? $\square$ Yes $\square$ No

15. If your answer to q14 is No. State reason(s)

Date:

Place:

Signature of the Doctor 